\title{
Mathematical and Circuit Modeling of the Human Cardiovascular and Ventilatory Kinetic Response in Exercise
}

\author{
Milan Stork \\ Department of Electronics and Information \\ Technology/RICE \\ University of West Bohemia \\ Plzen, Czech Republic \\ stork@kae.zcu.cz
}

\author{
Jaroslav Novak \\ Department of Sports Medicine \\ Medical Faculty in Plzen \\ Charles University in Prague \\ Plzen, Czech Republic \\ novakj@1fp.cuni.cz
}

\begin{abstract}
In this paper, we investigate a non-invasive procedure for static and dynamic modeling of cardiac output and oxygen consumption in response to cardiopulmonary exercise during exercise. The results are presented on 2 athletes - a football player and crosscountry runners who have undergone 10 stress tests for 5 years. The results can also be used to model some other physiological parameters. Measurements were performed in laboratory conditions that allowed measurable exercise settings and well-measurable load responses, such as heart rate, ventilation, and oxygen consumption.
\end{abstract}

Keywords - dynamic model; ergometer; cardiac output; heart frequency; oxygen consumption; sampling

\section{INTRODUCTION}

Cardiopulmonary exercise testing (CPET) allows non-invasive measurement of integrative exercise responses involving the pulmonary, cardiovascular, neuropsychological and skeletal muscle systems, which manifest themselves during the exercise test [1 4]. During exercise, some diseases can appear much earlier. Testing takes place on a bicycle or treadmill, using several intervals of increasing load on the bicycle, or speed and incline on the treadmill. Dynamic physiological models can be derived from the data obtained by this examination. These models can be used to assess both submaximal and peak exercise responses and provide physicians with relevant information for various clinical findings. CPET is increasingly used in a wide range of clinical applications to objectively determine functional capacity and some functional deficiencies. It should be emphasized that resting lung and cardiac functions cannot reliably predict a person's response to a stress test and functional capacity, and that overall health correlates better with exercise testing than with conventional at rest. CPET involves measurements of heart rate $(H R)$ oxygen uptake $\left(V \mathrm{O}_{2}\right)$, carbon dioxide $\left(\mathrm{VCO}_{2}\right)$ output and pulmonary ventilation during a gradual increase in exercise to a maximum (or to a

This work was supported by Department of Electronics and Information Technology/RICE, University of West Bohemia, Plzen, Czech Republic and by the Ministry of Education, Youth and Sports of the Czech Republic under the project OP VVV Electrical Engineering Technologies with High-Level of Embedded Intelligence, CZ.02.1.01/0.0/0.0/18_069/0009855 and by the Internal Grant Agency of University of West Bohemia in Plzen, the project SGS-2021-005. value limited by symptoms in patients) on some type of ergometer [5,6]. More than 5,000 examinations have been performed in the laboratory for both athletes and patients over a period of 30 years, while some subjects have undergone repeated testing to monitor the development of their fitness levels over several years. In Fig. 1, the photograph shows a CPET examination on a treadmill in a laboratory where heart frequency, electrocardiography (ECG), ventilation, blood pressure, oxygen consumption and carbon dioxide output were measured. From loads and measured parameters the mathematical model of $\mathrm{VO}_{2}$ was derived [7-9]. Also from load and measured $\mathrm{VO}_{2}$ the cardiac output $C O$ was non-invasively estimated and its mathematical models were derived. Bicycle work is quantified in watts [W] or in $(\mathrm{kpm} / \mathrm{min} ; 1 \mathrm{~W}=$ $\sim 6 \mathrm{kpm} / \mathrm{min})$.

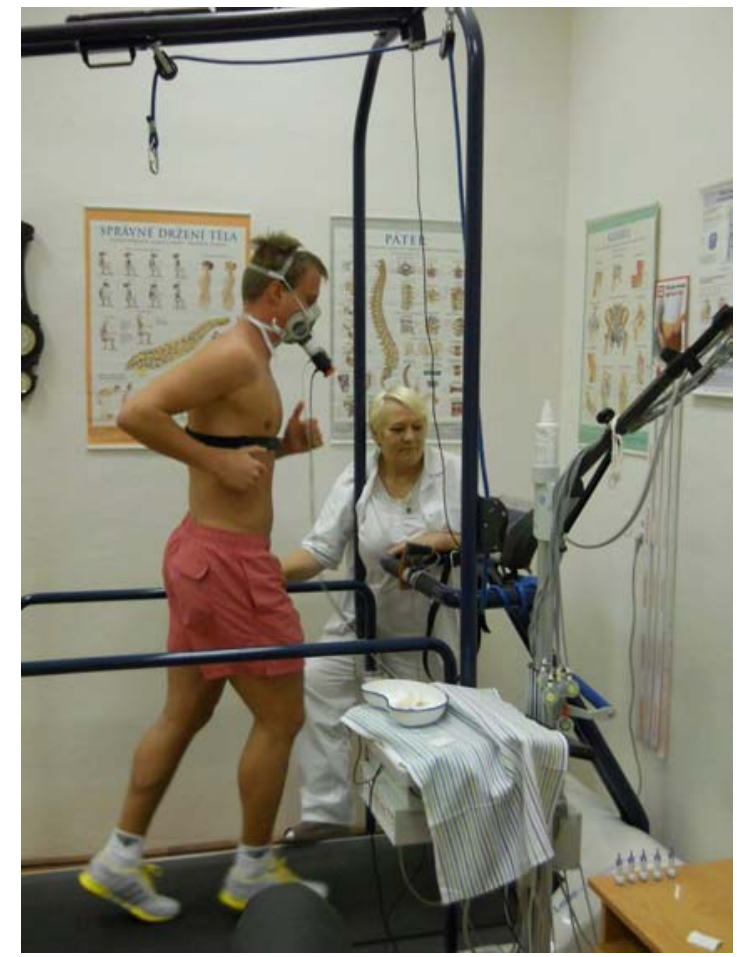

Figure 1. Photo of the athlet during cardiopulmonary test on a treadmill ergometer in a sport medicine laboratory. Basic physiological parameters are measured (sampling period is $10 \mathrm{sec}$ ), whereas blood pressure and lactate threshold are measured with longer sampling period 
Treadmill load is quantified in speed $[\mathrm{km} / \mathrm{h}]$ and slope [\%]. This work describes static and kinetic models of selected parameters based on repeated tests performed on the 2 types of ergometer over several years in 2 athletes.

\section{MATERIAL AND METHODS}

This chapter describes the stress test methods used. The method of loading on a bicycle ergometer is shown in Fig. 2, where several intervals with a gradually increasing load are used and then a linearly increasing load up to the maximum. When a treadmill ergometer is used, the dosing of the load is similar, with the difference that there are breaks for sampling for the determination of lactate. $\mathrm{CO}$ cannot be measured directly while cycling or running, but it can be non-invasively estimated from $\mathrm{VO}_{2}$ consumption. The appropriate load profile must be used, because maximum $V O_{2 \max }$ must be reached during examination. The $\mathrm{CO}$ estimation is based on $\mathrm{VO}_{2}$ measuring (calculated from ventilation and oxygen uptake) and then derived according the formula [7]:

$$
\mathrm{CO}\left(\mathrm{VO}_{2}\right)=\frac{100 \cdot \mathrm{VO}_{2}}{\left(5.72+0.1047 \frac{100 \cdot V \mathrm{O}_{2}}{V O_{2 M A X}}\right)}[1 / \mathrm{min}]
$$

The time evolution of load for bicycle ergometer is shown in Fig. 2. The time evolution for treadmill speed and grade is shown in Fig. 3. This exercise profile was used in all testing.

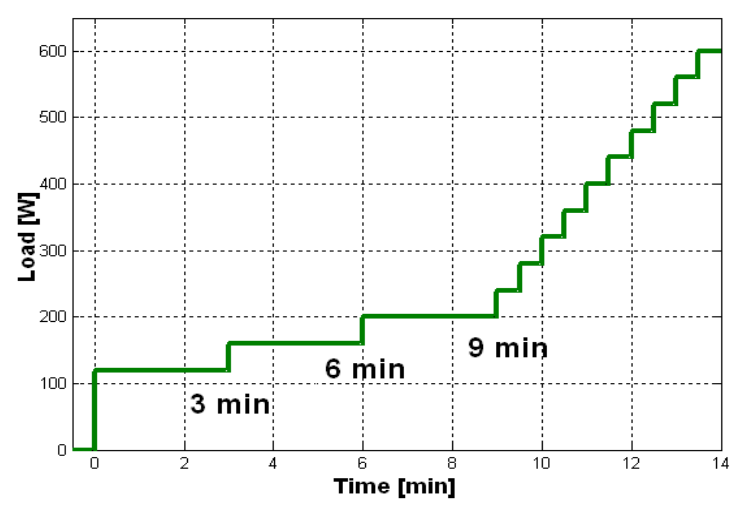

Figure 2. Load profile for bicycle examination. Whole load can be separated into 3 step loads (120,160 and $200 \mathrm{~W})$ and one linearly increasing load up to maximal load

Basic parameters of athletes for 10 tests applied over several years are:

Cross - country skier: Age $=18$ to 24 ; BMI: mean=22.9 $\mathrm{SD}=1.74$; He: mean=184 $\mathrm{SD}=5$; We: mean=77.7 $\mathrm{SD}=9.4 ; \mathrm{L}_{\mathrm{M}}:$ mean=499 $\mathrm{SD}=64 ; V O_{2 M A X}$ : mean $=5.88 \mathrm{SD}=0.77$

Football player: Age $=25$ to 31 ; BMI: mean $=24.9$ $\mathrm{SD}=0.52$; He: mean $=179 \mathrm{SD}=0.2 ;$ We: mean $=80$ $\mathrm{SD}=1.7 ; \mathrm{S}_{\mathrm{PM}}:$ mean=18 $\mathrm{SD}=0 ; V O_{2 M A X}:$ mean $=5.11$ $\mathrm{SD}=0.15$. Where $\mathrm{BMI}=$ Body Mass Index $\left[\mathrm{kg} / \mathrm{m}^{2}\right]$, $\mathrm{He}=$ Height $[\mathrm{cm}], \mathrm{We}=$ Weight $[\mathrm{kg}], \mathrm{L}_{\mathrm{M}}=$ Maximal load [W], $\mathrm{S}_{\mathrm{PM}}$ : Maximal speed $[\mathrm{km} / \mathrm{h}], V O_{2 M A X}=$ Maximal oxygen uptake [1/min] and SD is Standard deviation.

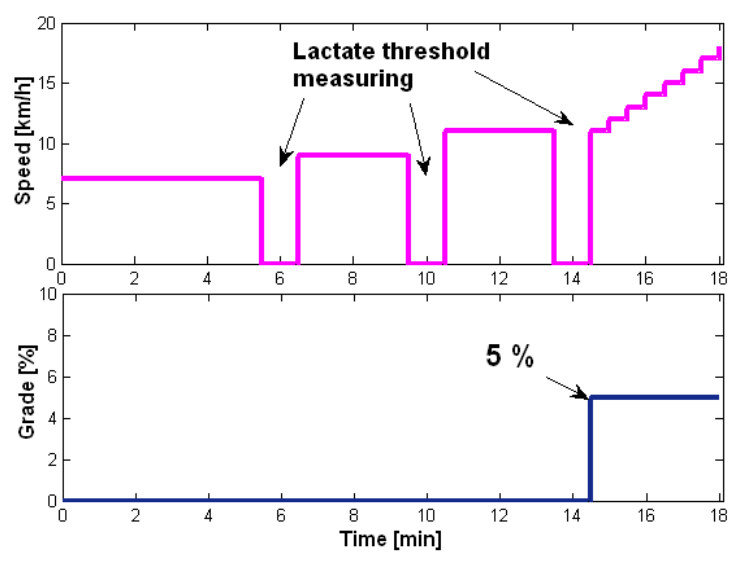

Figure 3. Load profile used for treadmill exercise (speed and grade, used in all 10 examinations). Workload speed profile including zero speed for lactate threshold measuring. Load profile can be separated into 3 step loads $(7,9$ and $11 \mathrm{~km} / \mathrm{h})$ with interrupts and final ramp load up to maximal load

\section{RESULTS}

In this first part of modeling, the static dependences of physiological parameters: $\mathrm{VO}_{2}, \mathrm{CO}$ and $H R$ on the load in the form of regression relationships are first derived from the 10 measured examinations (performed within 5 years). The linear regression equation of the dependence of $\mathrm{VO}_{2}$ on the load is

$$
\mathrm{VO}_{2}=0.0103 \cdot \mathrm{Load}+0.6 \quad[1 / \mathrm{min}, \mathrm{W}]
$$

The interdependence of $\mathrm{VO}_{2}$ and load (10 examinations), from which the regression relationship was derived, are shown in Fig. 4.

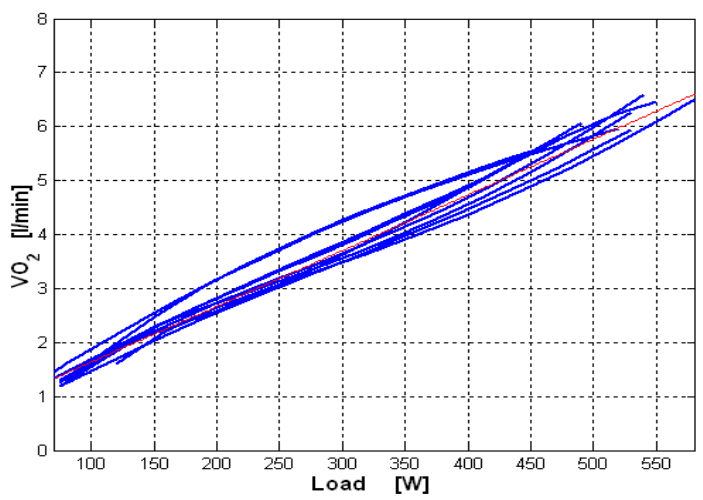

Figure 4. $\mathrm{VO}_{2}$ as function of load measured on bicycle ergometer

Similarly, the relationship for $C O$ dependence on load applies

$$
\begin{aligned}
& C O=1.788 \cdot 10^{-7} \cdot(\text { Load })^{3} \\
& -2.307 \cdot 10^{-4} \cdot(\text { Load })^{2} \\
& +0.1216 \cdot \text { Load }+8.4
\end{aligned}
$$

The regression formula (3) was derived from data, see Fig. 5. In this case, a nonlinear regression function was used. 


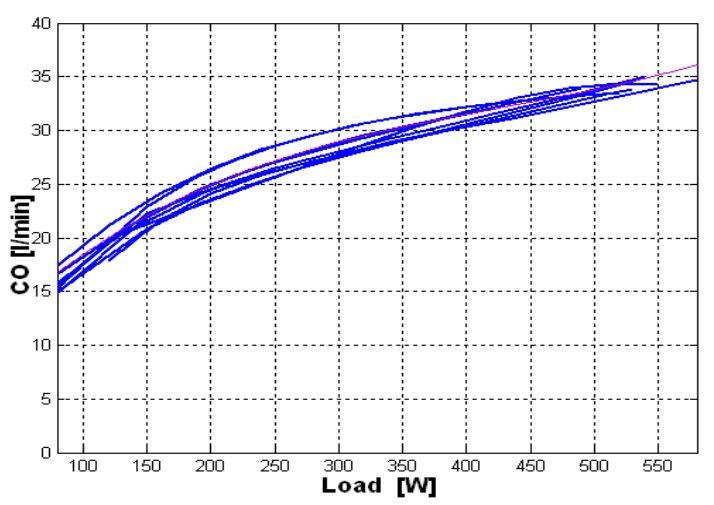

Figure 5. $\quad C O$ as function of load (for bicycle ergometer)

The regression equation of $H R$ dependence on the load is

$$
\begin{aligned}
& H R=3.32 \cdot 10^{-4} \cdot(\text { Load })^{2} \quad[\text { beat } / \mathrm{min}, \mathrm{W}] \\
& +0.39 \cdot \text { Load }+67.3
\end{aligned}
$$

Similarly, regression equations of $\mathrm{VO}_{2}, \mathrm{CO}$ and $\mathrm{HR}$ dependence on speed of a treadmill ergometer are derived. Therefore regression equation for $\mathrm{VO}_{2}$ is

$$
V \mathrm{O}_{2}=0.328 \cdot \text { Speed }-0.626[1 / \mathrm{min}, \mathrm{km} / \mathrm{h}]
$$

The examinations data from which the regression relationship was derived are shown in Fig. 6.

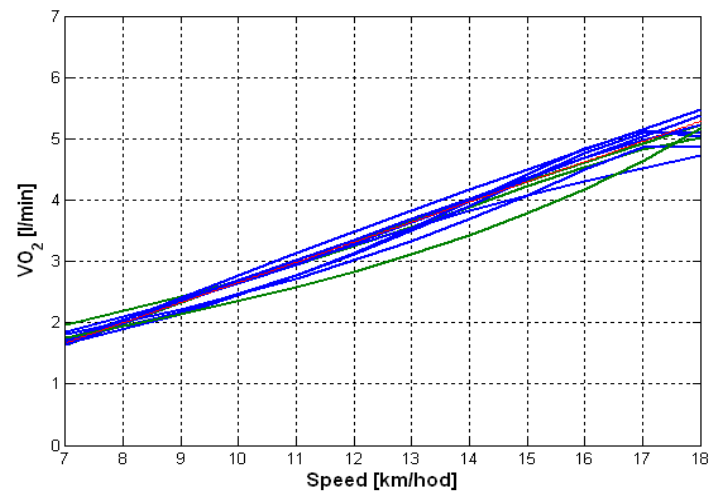

Figure 6. $\mathrm{VO}_{2}$ as function of speed measured on treadmill ergometer

Polynomial function for $\mathrm{CO}$ is (derived from data, see Fig. 7)

$$
\begin{aligned}
& C O=-0.0542 \cdot(\text { Speed })^{2} \\
& +2.68 \cdot \text { Speed }+1.39
\end{aligned}
$$

$[1 / \min , \mathrm{W}] \quad(6)$

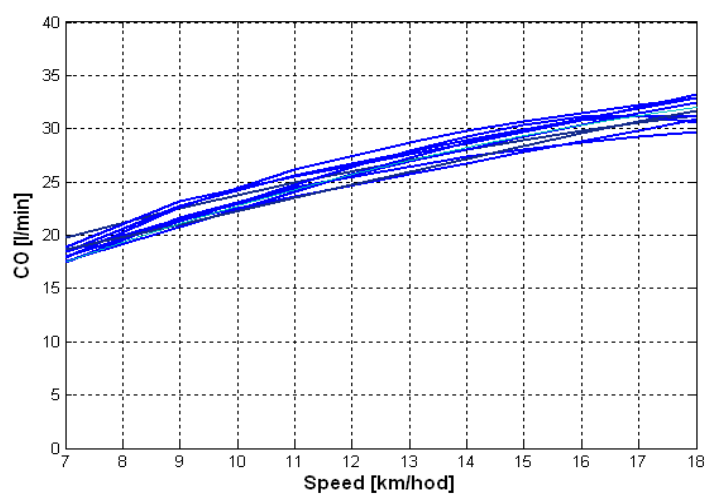

Figure 7. $C O$ as function of speed (for treadmill ergometer)
The regression equation of $H R$ dependence on the speed is

$$
\begin{aligned}
& H R=-0.0361 \cdot(\text { Speed })^{3} \\
& +1.09 \cdot(\text { Speed })^{2} \quad[\text { beat } / \mathrm{min}, \mathrm{km} / \mathrm{h}] \\
& -3.63 \cdot \text { Speed }+106
\end{aligned}
$$

The next section presents the results of dynamic $\mathrm{VO}_{2}$ models as a function of load and time $[10,11]$. First, a model for a bicycle ergometer is tested, where there is no load interruption during the lactate measurement. The second (more complex) is model for treadmill ergometer where speed is set to zero when the lactate thresholds are measured. The models can be searched as first-order systems with different time constants, gains and with internal delay. Input function (without ramp) is

$$
\begin{aligned}
& u(t)=K_{1}\left(1(t)-1\left(t-Z_{1,2}\right)\right) \\
& +K_{2}\left(1\left(t-Z_{2,1}\right)-1\left(t-Z_{2,2}\right)\right) \\
& +K_{n-1}\left(1\left(t-Z_{n-1,1}\right)-1\left(t-Z_{n-1,2}\right)\right) \\
& +K_{n} \cdot 1\left(t-Z_{n, 1}\right)
\end{aligned}
$$

where $1(t-Z)$ is unit step with time delay $Z$. $1(t$ $Z)=0$ for $(t-Z) \leq 0$.

Usually the traditional approach for model identification is not used because small sample set of exercise intensities. The Laplace transform of the first order models with different gains and time constants (which are used for modelling) is

$$
\begin{aligned}
& Y(s)=\left(\exp \left(-Z_{1,1} s\right)-\exp \left(-Z_{1,2} s\right)\right) \frac{K_{1}}{s\left(\tau_{1} s+1\right)} \\
& +\left(\exp \left(-Z_{2,1} s\right)-\exp \left(-Z_{2,2} s\right)\right) \frac{K_{2}}{s\left(\tau_{2} s+1\right)}+ \\
& \cdots\left(\exp \left(-Z_{n-1,1} s\right)-\exp \left(-Z_{n-1,2} s\right)\right) \frac{K_{n-1}}{s\left(\tau_{n-1} s+1\right)} \\
& +\exp \left(-D_{n, 1} s\right) \frac{K_{n}}{s\left(\tau_{n} s+1\right)}
\end{aligned}
$$

The result of the inverse Laplace transform of the relation (9) is

$$
\begin{aligned}
& y(t)=K_{1}\left(1\left(t-Z_{1,1}\right)\left[1-\exp \left(\frac{t-Z_{1,1}}{\tau_{1}}\right)\right]\right) \\
& -K_{1}\left(1\left(t-Z_{1,2}\right)\left[1-\exp \left(\frac{t-Z_{1,2}}{\tau_{2}}\right)\right]\right) \\
& \cdots+K_{n}\left(1\left(t-Z_{n, 1}\right)\left[1-\exp \left(\frac{t-Z_{n, 1}}{\tau_{n}}\right)\right]\right)
\end{aligned}
$$

The results of kinetic modelling of $\mathrm{VO} 2$ for bicycle and treadmill ergometers are displayed in Fig. 8 (for bicycle) and in Fig. 9 (for treadmill with interrupts). The measured time courses, simulated time courses, time constants and individual gains are presented below. 


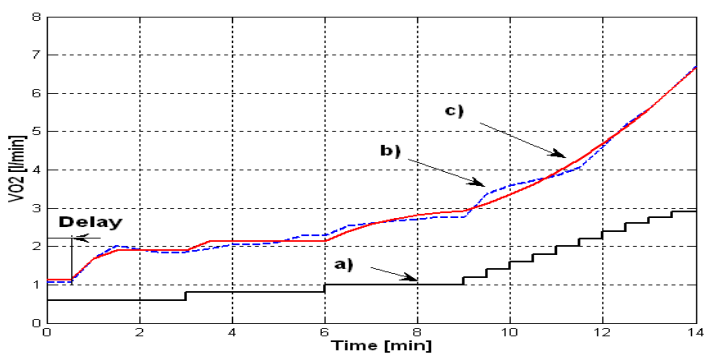

Figure 8. $\mathrm{VO}_{2}$ kinetic measured on bicycle ergometer, a) Load/200, b) Measured values (dash, blue), c) Model response (solid, red)

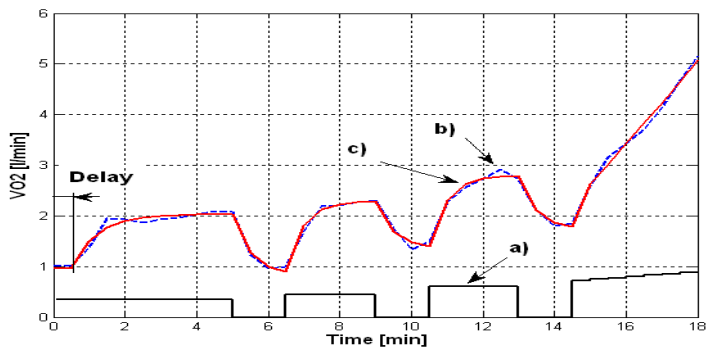

Figure 9. $\mathrm{VO}_{2}$ kinetic measured on treadmill ergometer, with interrupts for lactate threshold measuring, a) Speed/20, b)

Measured values (dash, blue), c) Model response (solid, red)

The time delay, gains and time constants for kinetic models were found by optimization methods from measured data. It was found that 2 different time constants are sufficient, longer at the beginning of the examination, shorter after warm up $\left(\tau_{1}=43 ; \tau_{2}=27[\mathrm{~s}]\right)$. Time delay was $\sim 28[\mathrm{~s}]$. The same method was used also for $C O$ model. The universal circuit diagram which can be used for simulation is shown in Fig, 10. The electronic version of the system is shown in Fig. 11. Signals presenting the load and oxygen dynamics are shown on the oscilloscope screen see in Fig. 12 (time scale - speed is 1300 times faster than in reality).

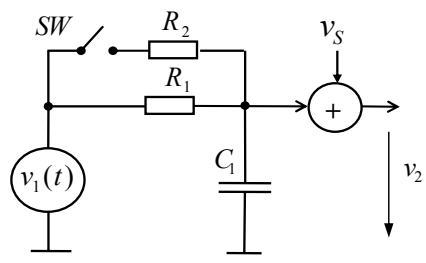

Figure 10. The circuit diagram for simulations of parameters $\mathrm{VO}_{2}$ and $C O$. SW - switch. Parameters for $V_{2}$ model are $R_{l}=0.36 \mathrm{M} \Omega$; $R_{2}=0.72 \mathrm{M} \Omega ; C_{1}=2 \mu \mathrm{F}$

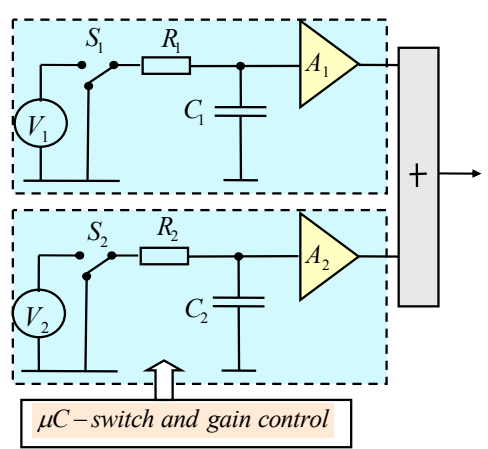

Figure 11. An electronic system that can be used to simulate physiological parameters ( $\mathrm{HR}, \mathrm{VO}_{2}, \mathrm{CO}$, etc.) during load. $\mu \mathrm{C}$ microcontroller, $A_{1}, A_{2}$ - gains, $S$-switch. The model consists of the same blocks, but with different component values.

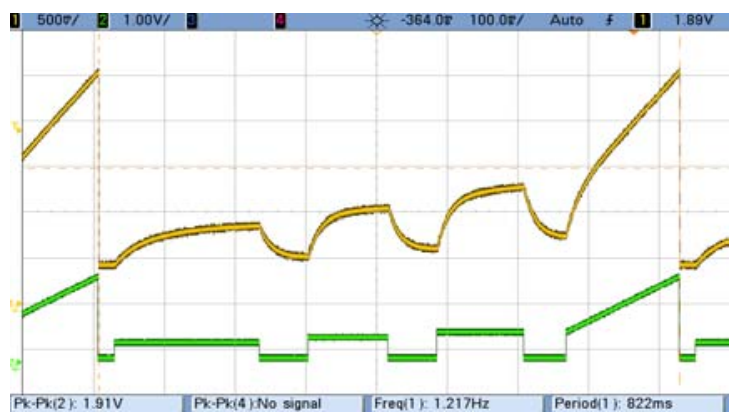

Figure 12. The copy of the oscilloscope screen. $\mathrm{VO}_{2}$ (top), load (bottom) - simulation by means of electrical circuit

\section{CONCLUSION}

In this work, the possibilities of static and dynamic modeling of some physiological parameters were based on the results of stress examinations. These models can be used to compare the level of training of athletes, the development of parameters during training, training dosage, but also for assessment of patient's condition. The system was implemented in a software version and also in a microcontroller with good results.

\section{REFERENCES}

[1] J. Porszasz, W. Stringer, R. Casaburi, "Equipment, measurements and quality control in clinical exercise testing," In: Ward SA, Palange P, eds. Clinical Exercise Testing. Eur Respir Mon 2007; 40: 108-128.

[2] K. Wasserman, J.E. Hansen, D.Y. Sue, et al., "Principles of Exercise Testing and Interpretation: Including Pathophysiology and Clinical Applications," Philadelphia, Lippincott Williams and Wilkins, 2005.

[3] H. Itoh, A. Tajima, A. Koike, et al., "Cardiopulmonary Exercise Testing and Cardiovascular Health," Armonk, Futura, 2002.

[4] A. Mezzani, "Cardiopulmonary Exercise Testing: Basics of Methodology and Measurements," Ann Am Thorac Soc Vol 14, Supplement 1, pp S3-S11, Jul 2017.

[5] B. J. Whipp, S. A. Ward, N. Lamarra, J. A. Davis, and K. Wasserman, "Parameters of ventilatory and gas exchange dynamics during exercise," Journal of Applied Physiology, vol. 52, no. 6, pp. 1506-1513, 1982.

[6] P. O. Astrand, K. Rodahl, H. A. Dahl, S. B. Stromme, "Text book of Work Physiology: Physiological of Bases of Exercise," 2003.

[7] W.W. Stringer, J. E. Hansen and K. Wasserman, "Cardiac output estimated noninvasively from oxygen uptake during exercise," J. Appl. Physiol. 82(3): 908-912, 1997.

[8] Lu Wang, W. Su, S. H. Chan and G. Celler, " A Mathematical Model of the Cardiovascular System under Exercise," Proceedings of the 29th Annual International Conference of the IEEE EMBS, Cité Internationale, Lyon, France, August 23-26, 2007

[9] M. Becker, P. Volkmer, M. Ali, E. Resendiz, D.Siregar, "Mathematical Model on Cardiovascular and Respiratory System, " Fachbereich Mathematik Technische Universitat Kaiserslautern, Summer 2004.

[10] K. Kour Buttar, N. Saboo and S. Kacker, "A review: Maximal oxygen uptake (VO2 max) and its estimation methods," International Journal of Physical Education, Sports and Health 2019; 6(6): pp. 24-32

[11] Baty et al., "Modeling the oxygen uptake kinetics during exercise testing of patients with chronic obstructive pulmonary diseases using nonlinear mixed models," BMC Medical Research Methodology, 2016 